\title{
LA ASOCIACIÓN Y EL DERECHO DE SOCIEDADES: NOTAS PARA UN DEBATE
}

\author{
SUSANA PÉREZ ESCALONA \\ Profesora Ayudante de Derecho Mercantil \\ Universidad de La Rioja
}

SUMARIO

I.- INTRODUCCIÓN II.- ¿ASOCIACIÓN VERSUS SOCIEDAD? 1. Identificación de la problemática. 2. El concepto amplio de sociedad. III.- LA DELIMITACIÓN CONCEPTUAL DEL LUCRO EN LAS ASOCIACIONES 1. Consideración general. 2. La inexistencia de lucro subjetivo en la asociación y la realización de actividades empresariales. IV.- CONCLUSIONES

\section{RESUMEN}

El presente artículo ensaya una conceptualización de la asociación como sociedad corporativa no capitalista, cuestionando la idoneidad del ánimo de lucro (arts. $1665 \mathrm{Cc}$ y $116 \mathrm{Cd} \mathrm{C}$ ) para desalojar el régimen jurídico de las asociaciones del ámbito del Derecho de Sociedades. Al tiempo, las páginas que siguen plantean el problema de la realización de actividades económicas por parte de las asociaciones en régimen de accesoriedad al fin común principal no lucrativo. 


\section{I.- INTRODUCCIÓN}

La reflexión generalizada sobre las asociaciones las ha mantenido aisladas del Derecho de sociedades porque, tradicionalmente, sociedad y asociación se han configurado (legislativa y doctrinalmente) como tipos (de organización social) conceptualmente contrapuestos en función de la calificación necesariamente lucrativa del fin común de la sociedad. Ello ha provocado que, salvo contribuciones doctrinales más o menos genéricas, no se haya atraído el estudio del régimen jurídico de las asociaciones al Derecho de sociedades, concebido éste como el ordenamiento (funcionalmente neutral) de las diferentes técnicas de organización de personas utilizadas para la conjunta promoción del fin común acordado ${ }^{1}$.

De esta forma, la tradicional expulsión del tipo social asociación del ámbito del Derecho de sociedades por la puerta de la inexistencia del ánimo de lucro (arts. $1665 \mathrm{Cc}$ y $116 \mathrm{Cd} \mathrm{C}$ ), ha conducido a efectos perversos. Así, es constatable como el secular diseño normativo del tipo como si la Ley de asociaciones no fuera, en realidad, una Ley de Derecho de sociedades ha condenado al análisis jurídico del tipo a un desarraigo doctrinal sin parangón dentro del Derecho privado ${ }^{2}$. Esta falta de atención iusprivatista, además, se

\footnotetext{
${ }^{1}$ Entre nosotros, las contribuciones doctrinales disponibles se refieren, fundamentalmente, al problema conceptual. Así, para una asimilación de la noción de asociación a la de sociedad. V. por ejemplo, GIRON; Derecho de sociedades; Tomo I, Parte General, Madrid, 1976, pp. 25-39; PAZ-ARES; “Ánimo de lucro y concepto de sociedad (Breves consideraciones a propósito del art. 2. $2^{\circ}$ LAIE)"; en AA.VV; Derecho Mercantil de la Comunidad Económica Europea (Estudios en Homenaje al Prof. José Girón Tena); Madrid, 1991, pp. 729753; Del mismo autor, en PAZ-ARES/ BERCOVITZ/ DÍEZ PICAZO/ SALVADOR CODERCH (dirs); Comentario del Código civil; Ministerio de Justicia, Tomo II, Madrid, 1991, pp. 1299 y ss, especialmente pp. 1307 y ss; Del mismo autor, "La sociedad en general: caracterización del contrato de sociedad"; en URIA/MENENDEZ; Curso de Derecho Mercantil I; Madrid, 1999, pp. 429 y ss, especialmente pp. 429-435; PAZ-ARES/ ALFARO; Manual Breve de Derecho Mercantil; Derecho de sociedades. Parte General, pendiente de publicación; PANTALEON; "Asociación y sociedad ( a propósito de una errata en el Código civil)"; $A D C$, 1993, enero-marzo, pp. 5-56, especialmente pp. 26 y 39-40. No obstante, son prácticamente anecdóticos los estudios que ubican concretamente el análisis del régimen jurídico de las asociaciones en la disciplina del Derecho de sociedades. Así, poniendo de manifiesto este lamentable estado de incuria del Derecho de asociaciones, en relación con el análisis de la expulsión de socios, por ejemplo, ALFARO; "La expulsión de asociados y la confianza en el Derecho Privado"; $A D C$, 1997, núm. 1, pp. 155-186, espcialmente pp. 158-159.

${ }^{2}$ La contraposición entre sociedad y asociación como categorías conceptuales irreductiblemente antíteticas ha provocado que los problemas derivados del régimen jurídico de las asociaciones hayan sido abordados, de forma general, al margen del Derecho de sociedades. Así, sin pretensión de exhaustividad, por lo que se refiere a manuales y monografías V. LLUIS Y NAVAS; Derecho de asociaciones; Barcelona, 1967; LÓPEZ NIETO Y MALLO; Manual de Asociaciones; Madrid, 1992; Del mismo autor, La ordenación legal de las asociaciones en España; Madrid, 1995; Sin modificaciones, del mismo autor, La ordenación legal de las asociaciones; Madrid, 2000; AA.VV (MARIN LÓPEZ, dir); Asociaciones, Fundaciones y Cooperativas; Madrid, 1995; MORA ALARCÓN; Derecho de Asociaciones; Madrid, 1999; CABANAS TREJO; Comentario de la Ley catalana de asociaciones; Madrid/ Barcelona, 2000; AA.VV (FLORENSÀ I TOMAS, Coord); Entitats Associatives en el Dret Civil Català; Lleida, 1993; FERNÁNDEZ FARRRERES; Asociaciones y Constitución; Madrid, 1987; VON MÜNCH/ FERRER I RIBA (SALVADOR CODERCH, Coord); Asociaciones: constitución y personalidad jurídica; Tesis Doctoral inédita; Facultad de Ciencias jurídicas y sociales (Toledo) de la Universidad de Castilla la Mancha; 1.991; BILBAO UBILLOS; Libertad de asociación y derechos de los socios; Valladolid, 1997; DE
} 
ha pagado, en términos generales, con un erróneo enfoque del régimen jurídico de las asociaciones que impide abordarlo desde una perspectiva esencialmente contractual aprovechando el caudal dogmático de las soluciones aportadas en el Derecho de las sociedades corporativas de capital (fundamentalmente SA y SL) como mecanismo integrador de lagunas ${ }^{3}$.

El objetivo perseguido en las páginas que siguen consiste, justamente, en conceptuar a la asociación como sociedad. Y la razón por la que nos decantamos por su asunción no puede hacerse esperar: si, como parece, $<<$ la realidad social del tiempo $>>$ (arg. ex art. 3 $\mathrm{Cc}$ ) ha provocado la contraposición entre sociedad y asociación como categorías conceptuales irreductiblemente antitéticas, desaparecido el contexto en el que la razón de control administrativo permitía contraponer conceptualmente sociedad y asociación en función de la índole (lucrativa o no) de su finalidad (art. $22 \mathrm{CE}$ ), la integración conceptual de la asociación está dotada de una racionalidad impecable y la incomunicación de regímenes jurídicos resulta valorativamente inaceptable.

SALAS MURILlO; Las asociaciones sin ánimo de lucro en el Derecho español; Madrid, Tesis Doctoral, 1999; GONZÁLEZ PÉREZ/ FERNÁNDEZ FARRERES; Derecho de asociación; Madrid, 2002.

3 Desde la naturaleza contractual del Derecho de sociedades, ha de afirmarse que la sociedad -y por tanto la asociación- es un contrato y, además, un mecanismo para contratar. Por ello, forzosamente reclama un generoso reconocimiento del principio de autonomía privada que se traduce en el carácter esencialmente dispositivo de su regulación y, por tanto, en la fijación de un marco normativo de mínimos dentro del cual los socios gozan de una amplia autonomía para adaptar la estructura del tipo a sus necesidades a través de los estatutos. Como es sabido, esta concepción parte del sistema nortamericano. Así, por ejemplo, EASTERBROOK/ FISCHEL; "The Corporate Contract"; Col. Law. Rev; 1989, pp. 1416 y ss. "We often speak (...) of the Corporation as a $<<$ nexus of contracts $>>$ or a set of implicit and explicit contracts. This reference, too, ist just a shorthand for the complex arragements of many sorts that those who associate voluntarily in the corporation will work among themselves" (p. 1418) [También en ROMANO (ed); Foundations of Corporate Law; New York/ Oxford, p. 103]; BECHUCK; "Limiting contractual freedom in Corporate Law: the desirable constrains on charter amendments" Harv. Law. Rev., 102 (1989); pp. 1820 y ss. " The Corporations is a contractual creature, a $<<$ nexus of contracts $>>$. This view of the Corporation (...) implies that the parties involved should be generally free to shape their contractual arragements. The function of corporate Law (...) should be to facilitate the process of private contracting by providing a set of $<<$ standars form $>>$ provisions. These standards-form provisions should be to facilitate the process of private contracting by providing a set of $<<$ standard-form $>>$ provisions. These standard-form provisions should not be mandatory, private parties should be free to adopt charter provisions opting out them" (pp. 1820-1821, con ulteriores referencias en notas núm. 1 y 2); TREBILCOCK; The limits of Freedom of Contract; Cambridge/ London, 1993 especialmente pp. 143 y ss; HANSMANN/ KRAAKMAN; "The esential role of organizational Law"; The Yale l. J; 3 (2000), pp. 387 y ss. Entre nosotros, por ejemplo, V. PAZ-ARES; ¿Cómo entendemos y cómo hacemos el Derecho de sociedades? (Reflexiones a propósito de la libertad contractual en la nueva LSL)", en (PAZ-ARES, Coord); Tratando de la Sociedad Limitada; Madrid, 1997, pp. 159 y ss; Del mismo autor, "La infracapitalización de sociedades: una aproximación contractual”; $R d S$, núm. extraordinario (1994); pp. 253 y ss[También en ALONSO UREBA (coord), ARTIGAS/ GARCIA VILLAVERDE (dirs); Derecho de sociedades de responsabilidad limitada; Madrid, 1996, I, pp. 65 y ss]; ALFARO; Interés social y derecho de suscripción preferente; Madrid, 1995, pp. 21-38; PERDICES; Claúsulas restrictivas de la libre transmisibilidad de acciones y de participaciones sociales; Madrid, 1997, pp. 25-29; CAMPIS; La Sociedad profesional; Madrid, 2000, pp. 111-116; MASSAGUER; "La autonomía privada y la configuración del régimen jurídico de la sociedad de responsabilidad limitada"; $R G D ; 1994$, pp. 1259 y ss, specialmente p. 1978; ALONSO ESPINOSA; "La sociedad de responsabilidad limitada ¿corporación personalizable?"; $R d S, 7$ (1996), pp. 31 y ss, especialmente pp. 33-34. 
Conviene hacer notar, no obstante, que el objetivo de consolidar la admisibilidad de un concepto amplio de sociedad en nuestro Derecho (desactivando las contundentes razones de Derecho positivo que se oponen hacia la viabilidad de una noción de sociedad a la que no le sea esencial la persecución del ánimo de lucro) constituye tan sólo la premisa metodológica desde la que afrontar el debate sobre la conveniencia de realojar a la asociación el campo del Derecho de sociedades. Así, parece evidente que a la corrección y oportunidad de este planteamiento integrador no podrá serle ajena, en último extremo, la tarea de mayor envergadura consistente en demostrar la benéfica influencia que, por razones de eficiencia normativa e interpretativa, es susceptible de ejercer el Derecho de sociedades en la configuración del régimen jurídico por el que han de regirse las asociaciones.

\section{II.- ¿ASOCIACIÓN VERSUS SOCIEDAD?}

\section{Identificación de la problemática}

Tradicionalmente, la Legislación especial de asociaciones ha circunscrito su ámbito objetivo de aplicación a las entidades que, por carecer de fin lucrativo, podían actuar como entidades eventualmente opuestas a la autoridad del Estado (arts. 1. $2^{\mathrm{o}}$ y $4^{\mathrm{o}}$ LOA) ${ }^{4}$. Esta exclusión, en principio, parece coherente con la idea, que es posible deducir de las definiciones legales de sociedad de que sólo hay sociedad si concurre ánimo de lucro (arts. $1665 \mathrm{Cc}$ y $116 \mathrm{Cde} C)^{5}$. Para un sector doctrinal, es esencial al concepto de sociedad la

\footnotetext{
4 Parece oportuno recordar, en este sentido, que el art. 1 de la LA de 30 de junio de 1887, que es la que tenía presente el redactor del Código Civil, disponía que $<<$ el derecho de asociación que reconoce el art. 13 de la Constitución podrá ejercitarse libremente conforme a lo que preceptúa esta Ley. En consecuencia, quedan sometidas a las disposiciones de la misma las asociaciones para fines religiosos, políticios, científicos, artísticos, benéficos y de recreo y cualesquiera otros lícitos que no tengan por úncio y exclusivo objeto el ánimo de lucro o ganancia $>>$ y el número 2 del art. 2 disponía que se exceptuaban del ámbito de aplicación de la Ley $<<$ las sociedades que no siendo de las enumeradas en el art. 1se propongan un objeto meramente civil o mercantil, en cuyo caso se regirán por las disposiciones del Derecho civil y mercantil respectivamente $>>$ (la cursiva es nuestra). Asimismo, el art. 2 de la LA de 24 de diciembre de 1964 disponía que <<quedan excluídas del ámbito de aplicación de esta Ley las entidades que se rijan por las disposiciones relativas al contrato de sociedad, según se define en las Leyes y se constituyan con arreglo al Derecho civil o mercantil $>>$. En el mismo sentido que la LOA se pronuncia la Legislación autonómica de asociaciones. Así, por ejemplo, los arts. 3. $1^{\circ}$ a) y $2^{\circ}$ de las Leyes de asociaciones vasca y catalana, respectivamente Consecuentemente, la finalidad de esta legislación especial ha venido siendo (en todos los oredanmiento jurídicos de corte latino) una finalidad política de control gubernativo. V. al respecto, por ejemplo; GIRON; Derecho de sociedades; pp. 31 y ss; PAZ-ARES; “Ánimo de lucro", p. 734 y nota núm. 8.

5 Al propio tiempo, ha de tenerse en cuenta que al disciplinar el fenómeno asociativo en sede de sistematización de las personas jurídica,s el Código civil se refiere metonímicamente exarts. 35 y 36 a las asociaciones de interés particular y de interés público, dando por presupuesta la definición de la categoría conceptual y disponiendo para las primeras -por (deducible) identidad de ratio- la aplicación del régimen jurídico del contrato de sociedad. Aunque la identificación entre ánimo de lucro e interés particular ha sido objeto de
} 
existencia de fin lucrativo y es precisamente la inexistencia de ánimo de lucro - o la inexistencia de la dimensión subjetiva del lucro- lo que distingue a la asociación de la sociedad $^{6}$. No obstante, como vamos a ver seguidamente, otro sector doctrinal ha

crítica desde todos los posicionamientos doctrinales, ha de destacarse que no existe acuerdo en cómo calificar a las asociaciones de estructura corporativa cuyo fin, no lucrativo, carezca de cualquier tipo de transcendencia social. Así, por ejemplo, PAZ-ARES; “Ánimo de lucro”, pp. 737-739, estima que se trata de asociaciones de interés público, dado que existe una conexión entre las asociaciones de estructura corporativa, las asociaciones sometidas a la Legislación especial de asociaciones y las asociaciones de interés público (p. 739, nota núm. 6); Para PANTALEON; "Asociación y sociedad”, pp. 21 y ss, sin embargo, se trata de asociaciones de interés particular (concepto amplio de interés particular) dado que, a su juicio, hay que reservar la noción de interés público para referirse a las entidades de estructura corporativa que persigan fines ideales (no lucrativos) de relevante transcendencia social, cuya actividad es una de la que las Administraciones públicas debe prestar a sus ciudadanos o fomentar su prestación mediante subvenciones directas o indirectas (p. 25). En todo caso, con independencia de la discrepancia en la denominación, ambos posicionamientos coinciden en lo esencial, esto es, en que no es conforme con las expectativas normativas de los socios aplicar en esa fenomenología de casos la disciplina del contrato de sociedad civil porque se trata de una normativa pensada para regir un tipo de estructura personalista. V. también, desde el planteamiento contrario de esencialidad conceptual del lucro a la noción de sociedad, FONT GALAN/ PINO ABAD; "La relevante causa negocial de la sociedad. Una relectura (sólo jurídica) del concepto legal de sociedad"; $R D M, 2001$, pp. 7 y ss, especialmente p. 14 y nota núm. 5.

${ }^{6}$ V. como ejemplos de esta doctrina tradicional, citando tan sólo dentro de los mercantilistas, GARRIGUES; "La capacidad para celebrar el contrato de asociación"; RDM, (1946), pp. 57 y ss; Del mismo autor, "Teoría General de las sociedades mercantiles"; RDM; (1976), pp. 519 y ss; DUQUE; "Societè, association et enterprise en droit spagnol"; en VERRUCOLI (ed); Evoluction et perspectives du droit des sociétés; Milano, 1968, pp. 79 y ss; MARTI SANCHEZ; "El contrato de sociedad en el Derecho codificado español con especial referencia al Código civil"; RDM, (1989), pp. 679 y ss, especialmente p. 680 en nota y p. 709; Del mismo autor, "El empresario social como sujeto de Derecho en el ordenamiento jurídico español"; $R D M$, (1994), pp. 119 y ss; BERCOVITZ/ BROSETA; "Mutuas de seguros, prima fija y carácter no mercantil”; RDM; (1986), pp. 31 y ss; VICENT-CHULIÂ; "Nota a la RDGRN de 25 de julio de 1992"; $R G D$; (1992), pp. 10280 y ss; BERCOVITZ, en BERCOVITZ (coord); La sociedad de responsabilidda limitada; Pamplona, 1998, pp. 33 y ss, especialmente pp. 75-76; PANIAGUA ZURERA; Mutualidad y lucro en la sociedad Cooperativa; Madrid, 1997, pp. 380-400, especialmente p. 383; DE LA CÁMARA; Estudios de Derecho Mercantil, I, Madrid (2), 1977, pp. 269 y ss; Del mismo autor, "El contrato de sociedad ¿crisis del concepto?"; ASN, VII, Madrid, 1993, pp. 425 y ss; FONT GALÁN/ PINO ABAD; "La relevante causa negocial de la sociedad”, pp. 7 y ss. V. ulteriores referencias a la doctrina civil y administrativa, que mantienen casi sin fisuras la esencialidad conceptual del lucro en PAZARES; “Ánimo de lucro"; p. 731, nota núm. 3; FONT GALAN/ PINO ABAD; "La relevante causa negocial”; pp. 10-12, nota núm. 1; GARCIA-PITA Y LASTRES; "Reflexiones sobre el concepto de sociedad y Derecho de Sociedades", $C D C, 33$ (2000), pp. 73 y ss, especialmente p. 191, nota núm. 309. Dentro de la doctrina tradicional, no obstante, es preciso distinguir entre los autores que conceptúan al ánimo de lucro en sentido estricto, como incremento del patrimonio divisible entre los socios y los autores que han pretendido dotar al concepto de cierta "elasticidad", configurándolo como cualquier tipo de ventaja económica para los socios, aunque no consista en un incremento del patrimonio. Esta $<<$ tercera vía $>>$ consistente en dilatar conceptualmente la noción de ánimo de lucro al objeto de no devaluar su esencialidad conceptual ha sido adoptada en el ordenamiento francés. Así, la Loi 78-9 du 4 janv. 1978, mediante la cual se reforma la redacción originaria del art. 1832 del Code Civil, introduce un concepto amplio de ánimo de lucro que no tenga porqué consistir, necesariamente, en el reparto entre los socios. También en el ordenamiento italiano se ha ensayado con la propuesta de estirar conceptualmente el lucro, de forma que la noción de asociación quepa en el concepto de sociedad ex art. 2247 Codice Civile. V. al respecto, por ejemplo, MARASÀ; Le $<<$ società $>>$ senza scopo di lucro; Milano, 1984, especialmente pp. 73 y ss y 165 y ss; Del mismo autor, "Su una proposta di reforma dell'art. 2247 Cc"; Giur. Comm, 1 (1992), pp. 1005 y ss; CAMPOBASSO; “Associazione e attivitá di impresa”; Rov. Dir. Civ., 3 (1994), pp. 581 y ss; GALGANO; Le Società; Bologna, ed. 1996/7, Reimpresión, con modificaciones en esta parte, 2000, pp. 14-18. [V. infra III. $1]$. 
cuestionado la esencialidad de la índole lucrativa del fin para caracterizar conceptualmente a la sociedad. Y, poniendo en duda la inherencia del fin lucrativo a la noción de sociedad, estos autores niegan, al propio tiempo, la idoneidad del criterio de base causal para distinguir entre sociedad y asociación colocando en su lugar-por influencia del concepto alemán de sociedad- el criterio estructural ${ }^{7}$.

\section{El concepto amplio de sociedad}

Partiendo de la consideración de que la finalidad de la Legislación especial de asociaciones ha venido siendo (en todos los ordenamientos de corte latino) una finalidad politica de control gubernativo, el sector que podríamos denominar "renovador" de la doctrina afirma que el concepto de sociedad ha de construirse sobre bases estructurales y no causales, esto es, ha de definirse como un fenómeno organizativo causalmente neutral $\mathrm{y}$, por tanto, independiente de la indole material o naturaleza del fin común ${ }^{8}$. Esta

\footnotetext{
${ }^{7}$ Como es sabido, en el ordenamiento alemán la asociación constituye el modelo de organización societaria de estructura corporativa. Así concebida, la asociación es una sociedad (rectius, uno de los dos modelos de organización societaria) y no una entidad conceptualmente contrapuesta a la sociedad en función del ánimo de lucro. Así, los parágrafos 21 y 22 BGB distinguen dos tipos de asociaciones según que su objeto no sea (Nichtwirtschaftlicher Verein) o sí lo sea (Wirtschaftlicher Verein) la explotación (negocial) de una actividad económica de carácter principal. No obstante, el Derecho alemán quiere impedir que se constituyan asociaciones de fin económico principal y no aceesorio (Wirstchaftlicher Verein) bajo tipos distintos de los mercantiles y, por ello, es común la distinción de tres tipos. Así, por ejemplo, SCHMIDT; "Systemfragen des Vereinsrechts"; ZHR, 147 (1983), pp. 43-68, especialmente pp. 58-62; Del mismo autor, Gesellschaftsrecht, pp. 554-562, distingue, en primer lugar, a las asociaciones que ejercen una actividad económica como proveedoras de bienes y servicios para el mercado. Este tipo actúa en un campo de actividades en el que la colectividad espera una responsabilidad equiparable a la que el Legislador exige a las sociedades de capital (fundamentalmente SA y SL). En segundo lugar, se encuentran las asociaciones que ejercen una actividad económica dentro de un mercado interno cuyas actividades se asemejan a las que las que realizan las Cooperativas de consumo. Finalmente, se encuentran aquellas asociaciones que desempeñan funciones equiparables a las que dasrrollan las Cooperativas de trabajo asociado. Ampliamete desarrollados estos tres tipos en su obra, Verbandszweck und Rechtsfähigkeit im Vereinsrecht. Eine Studie über Erwerb und Verlust der RechtsFähigkeit nichtwirtschaftlicher und Wirstchaftlicher Vereine; Heidelberg, 1984, pp. 113-161. Así también, REUTER; "100 Bände BGHZ: Vereinsund Genossenschaftsrecht"; ZHR, 151 (1987), pp. 355- 395, especialmente pp. 357-362.

${ }^{8}$ La vertebración del Derecho de sociedades sobre bases estructurales y no causales arranca en nuestra doctrina de los trabajos del profesor GIRON; "Sociedades civiles y sociedades mercantiles: distinción y relaciones en Derecho español"; $R D M$, (1947), pp. 7 y ss.; Del mismo autor, "Sobre los conceptos de sociedad en nuestro Derecho"; RDP, (1954), pp. 369 y ss. Afirmaba ya en dicho trabajo que "la nota económico-lucrativa en la índole del fin común ha (a)parecido siempre en nuestra doctrina insoslayable. Y, en efecto, antes de la Ley de Sociedades Anónimas parece que no existían medios hábiles para hacer una interpretación distinta. Sin la Ley de Asociaciones podría haberse encontrado base para una interpretación modificativa. En el art. 1665 se habla de medios y parece aludirse a un fin económico (....) Pero en el art. 1666 no se requiere otra cosa respecto del fin (<<objeto >> significa aquí fin) sino su licitud" (pp. 374-375. La cursiva es nuestra). Continúa con los conceptos y tipos de sociedades en los Códigos civil y de comercio y sus relaciones"; en Estudios de Derecho Mercantil; Madrid, 1955, pp. 211 y ss y, finalmente, en Derecho de sociedades, I, pp. 25-39. Las tesis de GIRON fueron posteriormente acogidas, por ejemplo, por GONZÁLEZ ORDOÑEZ; "Los criterios del Derecho español sobre la distinción entre sociedad civil y sociedad mercantil y sus consecuencias prácticas"; $R D M$, (1956), pp. 69 y ss GARRIDO DE PALMA; "Hacia un nuevo enfoque jurídico de la sociedad civil"; RDP, (1972), pp. 767 y ss;
} 
definición de la sociedad como fenómeno organizativo causalmente neutral pasa, así, por devaluar la esencialidad conceptual de la índole material del fin a la categoría de una mera nota de caracterización del tipo legal (y sólo del tipo legal) de la sociedad civil. Esta devaluación se justifica, en opinión de esta postura, en orden a una doble argumentación: de un lado, la pérdida de fuerza del criterio del ánimo de lucro para definir el concepto de sociedad se explica en función de un planteamiento de Derecho positivo[(infra a)]. De otro, la irrelevancia o inesencialidad conceptual de la índole material del fin se explica por un planteamiento de coherencia interna del sistema de selección de la disciplina aplicable a los diversos fenómenos agrupacionales que refuerza expresamente el anterior [(infra b)].

\section{a) El planteamiento de Derecho positivo}

El planteamiento de Derecho positivo a favor de la desestructuración causal del sistema de Derecho de sociedades parte de ponderar la eficacia despolitizadora que supuso, para todos los fenómenos agrupacionales, el reconocimiento constitucional del derecho fundamental de asociación ex art $22 \mathrm{CE}$. Así, se afirma que los motivos que históricamente justificaron la reserva societaria a la finalidad lucrativa han perdido su valor en la actualidad porque, dado que la norma fundamental reconoce el derecho de asociación como un derecho de libertad (frente a los poderes públicos) y sin más limitaciones que las previstas en su texto, la función de vigilancia (intervención) administrativa que cumplía la Legislación especial de asociaciones carece de sentido tras la entrada en vigor de la Constitución. De esa forma, aunque no es dudoso que existan poderosos argumentos positivos contrarios a la asimilación conceptual entre sociedad y asociación, no es menos claro que el reconocimiento constitucional del derecho de asociación ex art. 22 CE supuso un importante hito histórico (quizás el más importante) en la configuración de nuestro

FERNÁNDEZ DE LA GÁNDARA; La atipicidad en el Derecho de sociedades; Zaragoza, 1977, especialmente pp. 300-303; GONDRA ROMERO; "Hacia una renovación de los estudios de Derecho de sociedades en la doctrina española"; RDM, 1976, pp. 350 y ss; RUBIO; Curso de Derecho de sociedades Anónimas; Madrid, 1964, p. 42; SÁNCHEZ CALERO; Curso de Derecho de Seguro Privado; Bilbao, I, 1964, especialmente p. 64; Delmismo autor; La determinación y la distribcuión del beneficio neto en la Sociedad Anónima; Roma/ Madrid, 1955, especialmente p. 133; Del mismo autor, Instituciones del Derecho Mercantil; Madrid, (ed. 2002), pp. 220223; PAZ-ARES; Comentario; pp. 1299 y ss, especialmente pp. 1307-1308; Del mismo autor, “Ánimo de lucro y concepto de sociedad", pp. 729-753; Del mismo autor, "Derecho de Sociedades" y "Sociedad Mercantil"; en Enciclopedia Jurídica Civitas; Maadrid, 1995, pp. 2251 y 6339-6342; Del mismo autor, Curso de Derecho Mercantil (I); pp. 429 y ss; Del mismo autor, "La Agrupación de Interés Económico no tiene ánimo de lucro para sí misma”; en PAU PEDRON (dir); Comentario a la Ley de Agrupaciones de Interés Económico; Madrid, 1992, pp. 36 y ss; Del mismo autor, "La claúsula no lucrativa en la Ley de Agrupaciones de Interés Económico"; en Estudios en homenaje a L.Mateo II, 1993, pp. 265 y ss; PANTALEON; “Asociación y sociedad”, pp. 26 y 39 40; ALFARO; "Introducción y parte general”; Memento de Derecho de Sociedades; Madrid, 1995, núm. 71, pp. 11 y ss; CAMPIS; La sociedad profesional; pp. 38-39 y 105-106; EIZAGUIRRE; Derecho de sociedades; Madrid, 2001, Capit. I; MENENDEZ; Ensayo sobre la evolución actual de la Sociedad Anónima; Madrid, 1974, p. 65; MENENDEZ/ RODRIGUEZ ARTIGAS; “Disposiciones generales (art. 3 LSL)” en URIA/ MENENDEZ/ OLIVENCIA (dirs); Comentario al régimen legal de las sociedades mercantiles; Madrid, 1999, pp. 78-94, especialmente pp. 84-88; Matizadamente, no obstante, en "Sociedad Anónima y fin de lucro"; en AA.VV; Estudios jurídicos sobre al Sociedad Anónima; Madrid, 1995, pp. 39-59. 
Derecho de sociedades porque es en dicho precepto -y no en el art. 38 CE- donde actualmente cabe residenciar el fundamento constitucional del entero Derecho de sociedades ${ }^{9}$.

A nuestro juicio, ése es el argumento de mayor relevancia. Efectivamente, el reconocimiento constitucional del derecho de asociación tuvo la significación de proteger globalmente todas las (lícitas) manifestaciones agrupacionales (asociativas y societarias, al menos, en sus aspectos no patrimoniales) configurando un ámbito de autonomía colectiva -derecho de libertad- frente a los poderes públicos. Esto sólo puede significar que, para la norma fundamental, la noción de asociación se refiere a un género, dentro del cual, será el legislador llamado a completar la obra del constituyente (orgánico u ordinario) ${ }^{10}$ el

9 Así, por ejemplo, PAZ-ARES; Comentario; "La norma constitucional, en efecto, al reconocer el derecho de asociación está empleando la expresión en un sentido genérico, que abraza todas posibilidades asociativas y societarias. Entendemos, no obstante, que desde el punto de vista normativo esta terminología puede inducir a confusión. La razón se comprende sin esfuerzo: la disciplina de la asociación, en sentido genérico, que tendría que absorber la fenomenología atípica se halla en el régimen de la sociedad" (pp. 1302, 1344, 1358-1359); También en, "Ánimo de lucro", pp. 734-735; MENENDEZ; "Sociedad Anónima y fin de lucro", p. 46; También, entre otros, PANTAEON; "Asociación y sociedad". Precisa este autor en nota que "es opinión dominante que el art. 22 tutela también a las sociedades (...) no es esta la ocasión para discutir si la protección constitucional de las sociedades que ejercitan actividades económicas es tan extensa como la de las asociaciones estatutarias (....) La STC $23 / 1987$, de 23 de febrero, distinguió al efecto entre sociedades de personas y sociedades de capitales lo que, a mi juicio, tiene muy poco sentido" (p. 53, en nota); CAPILLA; La persona jurídica. Funciones y disfunciones; Madrid, 1984, pp. 118-119; PINO ABAD; La sociedad de capital no inscrita. La sociedad en formación y la sociedad irregular; Madrid/ Barcelona, 1999, pp. 128-132, especialmente p. 131; SÁNCHEZ ALVAREZ; La fundación de la Sociedad Anónima;Madrid, 1996, pp. 82-83; GARCIA-PITA Y LASTRES; "Reflexiones sobre el concepto de sociedad", p. 107.

Como es sabido, el TC se pronució originariamente sobre esta cuestión en su STC 23/1987, de 23 de febrero, afirmando que $<<$ si bien podría parecer a primera vista que nada se opone a que el término Asociación usado en el art. 22 de la Constitución en un sentido amplio presente en nuestro Código civil (...) comprendiera tanto las uniones de personas de finalidad no lucrativa como las de fines lucrativos, en realidad, aunque se admitiera esa apertura de fines de ese derecho fundamental, éste sólo podría invocarse en aquellos casos en los que apareciese vulnerado su contenido. $\mathrm{Y}$ en las sociedades mercantiles, y en particular en las sociedades de capitales, cuya forma más caracterísitica es la Sociedad Anónima, predomina, frente a las relaciones derivadas de la unión de personas, las nacidas de la unión de capitales, por lo que sin excluir la posibilidad de que, en determinados casos, pueda producirse una lesión del derecho de asociación respecto a este tipo de sociedades, es necesario plantear en cada supuesto si el derecho lesionado es de naturaleza asociativa o tiene un carácter preferentemente económico, quedando en esete segundo caso fuera del art. 22 de la Constitución $>>$ (La cursiva es nuestra). Siguiendo este discutible modo de razonar, asimismo, la Exp. de M. de la LOAafirma que $<<$ La presente Ley Orgánica, siguiendo nuestra tradición jurídica, limita su ámbito de aplicación a las asociaciones sin fin de lucro, lo que permite dejar fuera del ámbito de aplicación de la misma a las sociedades civiles, mercantiles, industriales y laborales, a las cooperativas y mutualidades y a las comunidades de bienes o de propietarios, cuyas finalidades y naturaleza no responden a la esencia comunmente aceptada de las asociaciones sin perjuicio de reconocer que el art. 22 de la Constitución podrá proyectar tangencialmente su ámbito protector cuando en este tipo de entidades se contemplen derechos que no tengan carácter patrimonial" (La cursiva es nuestra).

${ }^{10}$ La delimitación del desarrollo orgánico del derecho de asociación con anterioridad a la promulgación de la Ley Orgánica de Asociaciones fue objeto de particular atención doctrinal en relación con el problema del reparto de competencias normativas entre el Estado y las Comunidades Autónomas en materia de asociaciones. V., a raíz de la STC 173/1998, de 23 de julio, que resolvió el recurso de inconstitucionalidad contra la Ley vasca de 
encargado de diversificar especies y, consecuentemente, de caracterizar tipológicamente los diversos fenómenos agrupacionales que es posible incluir dentro de esa estructura genérica. Nos parece innegable, por ello, que la relevancia despolitizadora de la proclamación constitucional del derecho constituye un argumento lo suficientemente potente como para bascular sobre sí mismo la pérdida de relevancia conceptualizadora del ánimo de lucro pese a que se haya afirmado que "la $<<$ apertura constitucional $>>$ de esa $<<$ puerta histórica $>>$ no exonera al sector renovador de nuestra disciplina positiva para superar de lega lata la separación de dos instituciones, sociedad y asociación que (....) no caben en un solo concepto" $" 11$.

En efecto, sólo teniendo como brújula esa (histórica) pérdida de función del ánimo de lucro para acotar un espacio de fenómenos agrupacionales necesitados de especial vigilancia (intervención) administrativa se explica la evidente fractura que, en los conceptos normativos de sociedad (arts $1665 \mathrm{Cc}$ y $116 \mathrm{Cde}$ C) ha provocado, irreversiblemente, el reconocimiento legislativo de la plena fungibilidad causal de las Sociedades Anónimas y de las Sociedades de Responsabilidad Limitada (arts. 3 LSA y LSL), del carácter societario de las Agrupaciones de Interés Económico (arts. 2. $2^{\circ}$ LAIE), de las Cooperativas (art. 1 LCoop), de la Sociedad de Garantía Recíproca (arts. 2 y 4 LSGR) o de las Sociedades Anónimas Deportivas (art. 19 LD y arts. $1^{\circ}$ y 2. $1^{\circ}$ RDSAD) ${ }^{12}$. Sólo desde la

asociaciones, por ejemplo, LUCAS MURILLO DE LA CUEVA; Igualdad y autonomía. Las competencias sobre asociaciones en la Jusrirspudencia del Tribunal Constitucional; Madrid, 1999; Del mismo autor, "Delimitación de la competencia autonómica para la regulación de los derechos fundamentales"; RDPol, 1999, núm. 46, pp. 11 y ss; DE PABLO CONTRERAS; "La Legislación civil y la competencia autonómica en materia de asociaciones (a propósito de la STC 173/1998, de 23 de julio); RATC; 1999, Tomo I, pp. 1843 y ss; GERPE LANDIN/ FERNÁNDEZ DE FRUTOS/ MATEU Y VILASECA/ RIDRIGUEZ SANTAMARIA/ VALLÉS VIVES; "La delimitaciò de la capacitat normativa autonòmica en materia d'associacions (comentari de la STC 173/1998, de 23 de julio sobre la Lllei basca d'associacions)"; RJC, 1999, junio, pp. 7165 y ss; VIVANCOS COMES; "Notas sobre la Sentencia de la Ley vasca de asociaciones (a propósito de la Sentencia Constitucional 173/1998, de 23 de julio)"; $R G D$; 1999, pp. 7165 y ss. Asímismo, con indicaciones de la literatura anterior a dicho pronunciamiento constitucional, PÉREZ ESCALONA; "La fuentes del derecho de asociación (Comentario a la STC 173/1998, de 23 de julio)"; RCDI, 659 (2000), pp. 1979 y ss.

${ }^{11}$ Cfr. MENENDEZ; "Sociedad Anónima y fin de lucro"; p. 47. Incluso, como ya afirmara GIRON; Derecho de sociedades; con anterioridad a la entrada en vigor de la Constitución, en la Legislación especial de asociaciones "no se ve un interés del legislador en que no puedan organizarse, con estructura de sociedad, las figuras lucrativas ni al contrario, que las lucrativas no puedan servirse de estructuras corporativas. No hay un interés por ofrecer un régimen organizativo para las relaciones entre los súbditos, sino un interés externo de policía. Hay sólo un reflejo histórico de una cautela gubernativa respecto a qué agrupaciones se estima conveniente controlar, entendiéndose que las de fin económico no interesan a los políticos y que, contrariamente, las de fines no lucrativos podrían disimular éstos o implicar en ellos fines de aquel carácter que el Estado quiere preventivamente someter a su política" (p. 41).

${ }^{12}$ Con el criterio de mercantilidad por razón de la forma se pretende, precisamente, superar el criterio del objeto como determinante de la atribución de mercantilidad. Como es sabido, el debate sobre si las actividades no lucrativas pueden ser objeto de las Sociedades Anónimas y Limitadas ha dado origen a una abundante bibliografía que, mayoritariamente, se inclina por su admisión. Así, V. sobre la plena fungibilidad causal de las SA y SL, por ejemplo, FERNÁNDEZ DE LA GÁNDARA; Atipicidad; pp. 293-294; PAZ-ARES; Comentario, pp. 1376 y ss; Del mismo autor, "Sociedad mercantil"; EJC, IV, pp. 63398 y ss; Del mismo autor, Curso de Derecho Mercantil, p. 497; CAMARA; "Fundación: escritura y estatutos. Suscripción y desembolso"; en AA.VV; La reforma del Derecho español de sociedades de capital; Madrid, 1987, pp. 61 y ss, especialmete pp. 
despolitización del criterio del ánimo de lucro para trazar la frontera conceptual entre sociedad y asociación se puede reinterpretar, en suma, la literalidad de los conceptos de sociedad recogidos en los Códigos otorgando, al tiempo, sentido, a los preceptos del régimen jurídico de la sociedad civil que chocan con la interpretación tradicional ${ }^{13}$.

\section{b) El argumento de la selección de la disciplina aplicable}

De otra parte, de seguir la estricta acotación de las sociedades a los fenómenos lucrativos, resulta claro que debería aplicarse a ciertos fenómenos societarios atípicos sin finalidad lucrativa $-<<$ varias fundaciones artísticas se asocian para organizar, sin ánimo de lucro, una exposición conjunta estableciéndose la organización precisa para ello, varias empresas se unen para poner en marcha una escuela de negocios sin ánimo lucrativo, estableciéndose en ambos casos la organización precisa para ello $>>^{14}$-, la Legislación de asociaciones. Sin embargo, aunque denominemos a esos supuestos como asociaciones $-y$ aquí se encuentra precisamente la razón que justifica la conveniencia de abordar los problemas del régimen jurídico desde la perspectiva del Derecho de sociedades- el problema es que la Legislación de asociaciones se configura para vertebrar la disciplina de un tipo corporativo dotado de personalidad jurídica plena (arts. 5, 10, 15, 17 y 18 LOA), autonomía patrimonial (art. 7. J LOA) y organigrama de funcionamiento interno (arts. 11 y 12 LOA), con un fin institucionalizado y despersonalizado acordado estatutariamente (arts. 7 y 16 LOA) y parece evidente que ninguno de estas circunstancias se acomoda al régimen jurídico aplicable a unos fenómenos agrupacionales en los que la relación social y la organización resultante del contrato se fundamenta sobre la individualidad de los socios.

101 y ss; SANCHEZ CALERO; en AA.VV (SANCHEZ CALERO, Dir); Comentarios a la Ley de Sociedades Anóbnimas, I, Disposiciones Generales. Fundación de la Sociedad y Aportaciones; Madrid, 1997, pp. 102 y ss, VELASCO SAN PEDRO; "Concepto y caracteres de la sociedad de responsabilidad limitada"; en AA.VV; Derecho de las sociedades de responsabilidad limitada, I, Madrid, 1996, pp. 39 y ss, especialmente p. 55; SANCHEZ ANDRES; "La acción y los derechos del accionista"; en URIA/ MENENDEZ/ OLIVENCIA (dirs); Comentario al régimen legal de las sociedades mercantiles; T. XIV, vol. $1^{\text { }}$ A; Madrid, 1999, art. 3 LSL, pp. 7894, especialmente pp. 82-88. Contra argumentando que los preceptos de la Legislación especial no dan pie para prescindir del ánimo de lucro en la conceptualización de la sociedad, por ejemplo, GARRIGUES/ OLIVENCIA; en GARRIGUES/ URIA; Comentario a la Ley de Sociedades Anónimas I; Madrid, 1976, pp. 130-131; BERCOVITZ; La Sociedad de Responsabilidad Limitada, pp. 75-78; FONT GALAN/ PINO ABAD; "La relevante causa negocial", pp. 69 y $70-76$;

13 Desde la perspectiva devaluadora del ánimo de lucro a la categoría de rasgo tipológico de la sociedad civil (y no del concepto de sociedad), se afirma que lo único que le piden los arts. 1665 y $1666 \mathrm{Cc}$ al fin social en el concepto de sociedad es que sea común (establecido en interés de todos los socios) y no que además tenga que ser necesariamente lucrativo. La función de concreción de la índole material del fin común del tipo (y sólo del tipo) de la sociedad civil la desempeña el art. 1691 Cc al disciplinar la proscripción de los pactos leoninos. Así, PAZARES; “Ánimo de lucro"; pp. 735-737. Un apunte también en GIRON; "Sobre los conceptos de sociedad”; p. 375; MENENDEZ; “Ánimo de lucro y concepto de sociedad”, pp. 45-47. Afirmando que la identidad causal del contrato de sociedad reside en la comunidad de fin y es, consecuentemente, una identidad causal fungible se alcanza a comprender, además, la inclusión de las sociedades universales dentro del régimen jurídico de las sociedades como un tipo especial de las mismas. Así, por todos, PA Z-ARES; Comentario, p. 1389.

${ }^{14}$ Ejemplos tomados de PAZ-ARES; “Ánimo de lucro”, pp. 743-744, reproducidos por PANTALEON; “Asociación y sociedad", p. 11. 
Son razones de adecuación a las expectativas normativas de las partes, en definitiva, las que obligan a construir un $<<$ prototipo normativo $>>$ de sociedad (fundamentado en tres elementos esenciales: el origen negocial, el fin común con independencia de su concreta índole material y la contribución de todos los socios a su consecución) en el que las asociaciones constituyan el modelo de sociedad corporativa, de la misma forma que la sociedad civil constituye el modelo de las sociedades personalistas ${ }^{15}$.

\section{c) Conclusiones intermedias}

Afirmar que el reconocimiento constitucional del derecho fundamental de asociación mudó radicalmente la perspectiva de tradicional vigilancia administrativa en la que se enmarcaba la regulación jurídica de las asociaciones no dejaría de ser una obviedad, si no fuera porque sobre (el alcance de) esa despolitización del género asociativo, un sector de la doctrina ha basculado la devaluación del ánimo de lucro como criterio de distinción entre sociedad y asociación y como elemento conceptual inherente a la noción de sociedad. De hecho, de todo lo expuesto hasta aquí se evidencia que el debate parece pender, en última instancia, del alcance del precepto constitucional para $<<$ despolitizar $>>$ el ánimo de lucro porque, la interpretación literal de los preceptos que se ocupan de definir la sociedad (arts. 1665 Cc y 116 Ccom), la sistematización normativa de las asociaciones susceptibles de adquirir personalidad jurídica (arts. 35 y $36 \mathrm{Cc}$ ), la Legislación de asociaciones (art. 1. $2^{\circ}$ y $4^{\circ}$ LOA), así como un importante sector doctrinal continúan haciendo descansar sobre el ánimo de lucro la distinción entre sociedad y asociación y confirmando su inherencia al concepto de sociedad.

Es cierto, asímismo, que prescindir del ánimo de lucro como elemento conceptual de la noción de sociedad puede parecer un tanto arriesgado en ausencia de una $<<$ Ley General de sociedades $>>$ que supere de una vez por todas la dicotomía conceptual que recogen los textos legales, en el sentido de acoger un concepto simplificado de sociedad, de cuya matriz deriven dos subgrupos de entidades diferenciadas en función del criterio de su estructuración: corporativa, para el tipo asociación y personalista, para el tipo sociedad civil porque, al fin y al cabo, los textos legales siguen reflejando, por muy trasnochados que nos

15 Así, GIRON; Derecho de sociedades; "La sociedad en sentido amplio se compone del mínimo de elementos (fin común, promovido por los socios, origen negocial). Luego, sociedad y asociación adicionan elementos a aquel mínimo y, además, se contraponen por la estructura técnuico jurídica de organización que una y otra revisten. Pero esas figuras, como formas de organización no se encuentran condicionadas por la índole material del fin. Para fines no económicos pueden ser adecuadas o no fórmulas de sociedad o fórmulas corporativas. Es la magnitud y el grado de despersonalización e institucionalización del fin lo que influye en la modalidad de organización en un sentido o en otro" (pp. 29 y 35); PAZ-ARES; Comentario, pp. 1306-1307; 1453-1454; Del mismo autor, “'Ánimo de lucro"; pp. 731-733; Del mismo autor, Curso de Derecho Mercantil; pp. 429-435; Del mismo autor en, Comentarios LAIE; p. 16; PANTALEON; “Asociación y sociedad”; pp. 26 y 47; FERNÁNDEZ DE LA GÁNDARA; Atipicidad, pp. 339 y ss; MENENDEZ; "Sociedad ánónima y fin de lucro", pp. 44-45. 
puedan llegar a parecer, la concepción latina de la necesaria índole lucrativa de la finalidad de la sociedad ${ }^{16}$.

Con ser cierto todo lo expuesto, a nuestro juicio, no lo es menos que articular la distinción entre sociedad y asociación sobre el ánimo de lucro, configurándolo como esencial a la definición de sociedad no puede continuar sosteniéndose. En el plano de los conceptos, no hay ninguna razón significativa que justifique esa antítesis vertebrada sobre el ánimo de lucro, cualquiera que sea la amplitud conceptual del mismo; y no la hay porque, en el plano de selección de la disciplina aplicable, resulta manifiestamente improcedente (por contravenir las expectativas normativas de las partes) aplicar el Derecho de asociaciones a los fenómenos asociativos sin ánimo de lucro en todos caso. Desde esta perspectiva de configuración del régimen jurídico aplicable, las nociones de sociedad y asociación ni son ni pueden ser antitéticas. Las asociaciones son sociedades. Es más son uno de los moldes o modelos de sociedad en torno a los cuales se agrupan todos los (numerus clausus) de tipos sociales posibles porque lo específico del concepto de sociedad ha de buscarse en la existencia de una estructura corporativa y no en la ausencia de finalidad lucrativa de la misma. Cuando dicha sociedad corporativa sin ánimo de lucro carezca de capital, entonces, será aplicable la legislación de asociaciones, sin perjuicio de que dentro del molde legal quepan, naturalmente, las más amplias posibilidades de personalización del tipo.

Estamos convencidos, en este sentido, de que en la actualidad la única articulación del Derecho de sociedades (y asociaciones) apta para seleccionar adecuadamente la disciplina

\footnotetext{
16 Como es sabido, la pretensión de elaborar una Ley General de sociedades que "sirviera tanto para perfilar la delimitación de los diversos tipos sociales dentro de nuestro ordenamiento que, con el tiempo van mostrando más elementos comunes, como para generalizar ciertas normas de Derecho de sociedades, al tiempo de dar una adecuada disciplina de cada uno de los tipos que caben dentro de su ámbito" constituye una recurrente aspiranción doctrinal a la hora de proponer soluciones en la resolución del denominado problema tipológico. Así, SANCHEZ CALERO; "Derecho de las sociedades de Responsabilidad limitada y el Derecho de la Sociedad Anónima. Una valoración de la reforma”, en Tratando, pp. 1257 y ss, $c f r$. p. 1270. No obstante, como recoge este autor, los trabajos de unificación se han centrado en la elaboración de un Anteproyecto de Ley de Sociedades mercantiles porque "aun comprendiendo que sería de desear la existencia de una Ley comprensiva de toda clase de sociedades, la limitación del anteproyecto de la Ley general a las sociedades mercantiles se debe (entre otras) a la circunstancia de la dificultad de construir dentro de nuestro ordenamiento un concepto amplio de sociedad que supere el contenido del art. 1665 Cc" (p. 1272). V., también, por ejemplo, MENENDEZ; “Algunas reflexiones sobre la reforma de la Ley de Sociedades de Responsabilidad Limitada"; en AA.VV; MENENDEZ (dir.); ¿Sociedad Anónima o Sociedad de Responsabilidad Limitada?; Madrid, 1992, pp. 239 y ss; MENENDEZ/ RODRIGUEZ ARTIGAS; en Comentario al régimen legal de las sociedades mercantiles; Tomo XIV, vol. $1^{\circ}$, pp. 42-46; GONDRA ROMERO; "La posición de la sociedad de responsabilidad limitada en la reforma del Derecho de sociedades", en AA.VV; La reforma del Derecho de sociedades de capital; Madrid, 1987, pp. 909 y ss; FERNÁNDEZ DE LA GÁNDARA; Atipicidad; pp. 464 y ss; Del mismo autor, "Tradición y reforma en el nuevo Derecho de sociedades de responsabilidad limitada"; en AA.VV; El nuevo régimen jurídico de la Sociedad Anónima; Madrid, 1991, pp. 163 y ss; Del mismo autor, "El problema tipológico: la consagración del sistema dualista. Sociedad Anónima- Sociedad de Responsabilidad Limitada"; RdS, núm. extraordinario (1994), pp. 35 y ss; Del mismo autor, "La Ley de sociedades de responsabilidad limitada: acto final"; $R d S 5$ (1995), pp. 11 y ss; OLIVENCIA, en Tratando, pp. 144-148, VIERA GONZALEZ; Las Sociedades de capital cerradas. Un problema de relaciones entre los tipos SA y SRL; Madrid, 2002, especialmente pp. 160 y ss.
} 
aplicable a los diversos fenómenos agrupacionales destinados a la conjunta promoción del fin común acordado es la que mira a la estructura (personalista o corporativa) del fenómeno agrupacional y no al ánimo de lucro. Es esa razón de selección de la disciplina aplicable y de integración de lagunas la que justifica, precisamente, la necesidad de acoger un concepto amplio de sociedad, dentro del cual, sólo a las sociedades corporativas sin ánimo de lucro no capitalistas devenga aplicable el Derecho de asociaciones, entendido como parte del Derecho (privado contractual) de sociedades.

Al margen, la configuración planteada por la doctrina que atiende a la estructura (expectativas normativas de las partes) del fenómeno societario resulta más acertada por los siguientes grupos de motivos:

(1) En primer lugar, la vertebración del Derecho de sociedades sobre bases estructurales pone de manifiesto que el género de los fenómenos societarios es la sociedad y no la asociación y que, por tanto, la disciplina genérica de ésta ha de encontrarse en aquella y no al revés. Y esto, ya de por sí, es mucho ${ }^{17}$. La hipótesis contraria, en efecto, no puede sostenerse porque supone que la asociación además de gozar de neutralidad estructural posee fungibilidad causal. Obviamente, la neutralidad estructural de la asociación debe afirmarse sin reservas en consonancia con las notas de polivalencia y flexibilidad funcional que caracterizan al Derecho de sociedades. Para ello, naturalmente, el diseño del modelo legal habrá de ser (interpretado como si fuera) susceptible de las más amplias posibilidades de personalización, al objeto de que los particulares puedan configurar la asociación que más se adapte a sus preferencias y deseos ${ }^{18}$. Pero la neutralidad causal de la asociación no es cierta, al menos, para todas las entidades susceptibles de ser conceptualizadas como asociación a la luz de lo previsto en la Legislación específica (art. 1. $2^{\circ}$ y $4^{\circ}$ LOA), so pena de violentar el principio de numerus clausus de tipos sociales existentes en nuestro Derecho. El reconocimiento constitucional del derecho de asociación tuvo la importantísima significación de "liberalizar" todo el espacio de los fenómenos agrupacionales para la conjunta promoción del fin común acordado, pero ello no fractura la consideración de que el ejercicio de la actividad mercantil

\footnotetext{
17 Contra, por ejemplo, O“CALLAGHAN; La persona no lucrativa tipo asociación"; en Asociaciones, fundaciones y cooperativas; pp. 9 y ss, especialmente p. 13; FERNÁNDEZ DE LA GÁNDARA; Atipicidad; p. 301; GARRIGUES; "Teoría general de las sociedades mercantiles", p. 8; MARTI SANCHEZ; "Aproximaciones al concepto de sociedad", p. 27; CAMARA; Estudios ; p. 269; Del mismo autor, "El contrato de sociedad"; p. 425; DUQUE; "Societè, association et enterprise", p. 83; PINO ABAD; "La discutida personalidad jurídica de las sociedades mercantiles no inscritas"; $C D C, 29$ (1999), especialmente p. 122 y nota núm. 106; PANIAGUA; Mutualidad y lucro, pp. 388-392; FONT GALAN/ PINO ABAD; "La relevante causa negocial de la sociedad", pp. $12,14,54,60$ y pp. 64 y ss.

18 Como es sabido, con las notas de fungibilidad y flexibilidad funcional del Derecho de sociedades se pretende significar que los particulares pueden elegir la forma social que mejor se ajuste a sus necesidades, dado que las figuras societarias son aplicables, en principio, a cualquier finalidad. Dada la naturaleza exquisitamente contractual del Derecho de sociedades, la función que ha cumplir el Legislador de Derecho de sociedades no es la ordenar a las partes la mejor manera posible de configurar la sociedad, sino la ayudarles en tal comfiguración diseñando un modelo $<<$ que les dispense de la tarea siempre costosa de fabricarse un traje a medida $>>$.V. por todos, PAZ-ARES; “¿Cómo entendemos y cómo hacemos el Derecho de sociedades?”; en Tratando, pp. 159 y ss [V. supra nota núm. 3]
} 
no puede llevarse a cabo fuera del rigor y de las garantías de los tipos mercantiles (art. 122 $\mathrm{CdC})^{19}$.

(2) La configuración expuesta, de otro lado, tiene la virtud de caracterizar el concepto de asociación como modelo de organización societaria de estructura corporativa. Y éste, indudablemente, es su mayor logro. En efecto, si se reputan suficientes los argumentos esgrimidos en aras a sostener la fungibilidad causal del contrato de sociedad y se tiene en cuenta que la Legislación especial de asociaciones constituye una normativa propia de asociaciones estructuradas corporativamente (arts. 7 y 11 LOA), parece coherente afirmar que el concepto de asociación queda reservado -como modalidad de organización societaria- para las sociedades de estructura corporativa organizadas estatutariamente ${ }^{20}$. Cuando estas sociedades se rijan por la Legislación especial de asociaciones habrán de perseguir una finalidad diferente de la lucrativa y carecer de capital social. Así, la asociación (lato sensu) es, por tanto, la forma o tipo básico de las sociedades estatutarias (de estructura corporativa) que cuando queden sometidas (stricto sensu) a la Legislación específica de asociaciones por carecer de capital social (arg. ex arts. 3 LSA y LSL) deberán perseguir una finalidad diferente de la lucrativa (arts. $1.2^{\circ}$ y $4^{\circ} \mathrm{LOA}$ ).

\section{III.- LA DELIMITACIÓN CONCEPTUAL DEL LUCRO EN LAS ASOCIACIONES}

\section{Consideración general}

Hasta el momento, hemos expuesto que el requisito de la inexistencia del ánimo de lucro no parece poseer relevancia conceptual para caracterizar el tipo social asociación, dado que al constituir un requisito caracterizador del fin común de las asociaciones sometidas a la legislación específica, la función que cumple este criterio se desplaza desde el plano conceptualizador al plano de la delimitación de la normativa aplicable. De esta forma, no es que la inexistencia del ánimo de lucro conceptúe a una entidad como asociación, es que sólo a las asociaciones (conceptuadas como tales por poseer estructura corporativa) que carezcan de ánimo de lucro y de capital les será aplicable una legislación

19 V. infra III.

20 Como es sabido, la estructura corporativa, por contraposición a la personalista constituye un modelo teórico de organización societaria caracterizado por la constitución de una organización objetivada que se establece al acordarse el estatuto en el negocio constitutivo, pasando a formar parte del contrato fundacional. Que la estructura corporativa se equipare a la constitución de una organización objetiva significa, por su parte, que el régimen jurídico de las formas sociales dotadas de este tipo de organización se construye desconectadamente (con abstracción) de la identidad personal de los socios en cada momento y, por tanto, que el fin común se independiza (institucionalizándose), dado que lo relevante es la organización derivada del contrato y no el elemento subjetivo de los socios. . V. por ejemplo, GIRON; Apuntes de Derecho Mercantil; Madrid, 1985 , Vol. $1^{\circ}$, p. 6; Del mismo autor, Derecho de sociedades, pp. 29, 176-177 y 279; PAZ-ARES; Curso, p. 485; ALONSO ESPINOSA; "La Sociedad de Responsabilidad Limitada ¿Corporación personalizable?”, pp. 34-39. 
especial pensada, lógicamente, para vertebrar (al menos parcialmente) el régimen jurídico de las entidades organizadas conforme a esquemas corporativos y no personalistas. Así las cosas, elevar a rasgo conceptual principal la estructura corporativa permite cubrir las lagunas del régimen jurídico de las asociaciones con la aplicación analógica del régimen jurídico de las sociedades anónimas y limitadas, respetando las especialidades de la asociación (fundamentalmente, la inexistencia de capital que cumpla las funciones de fondo de producción y garantías típicas de la Sociedad Anónima o Limitada). Aplicación analógica que, desde la consideración de la asociación como sociedad de estructura corporativa, se encuentra plenamente legitimada y procederá cuando falte regulación estatutaria o legal aplicable ${ }^{21}$. Ahora bien, intencionadamente hemos explicado la doctrina que sostiene la inidoneidad del ánimo de lucro al concepto de sociedad (y la consiguiente pérdida de relevancia del criterio del ánimo de lucro para articular la distinción entre sociedad y asociación) abstrayendo el debate de la concreta extensión conceptual del lucro. Como podrá apreciarse seguidamente no ha sido casual plantear la hipótesis de la irrelevancia ceteris paribus de la extensión conceptual del ánimo de lucro para explicar la degradación de ese elemento como parámetro de distinción entre sociedad y asociación.

\section{La inexistencia de lucro subjetivo en la asociación y la realización de actividades empresariales.}

La determinación de la amplitud conceptual del lucro (en Derecho de sociedades en general y a efectos de lo previsto en la Legislación de asociaciones en particular) es especialmente compleja porque las disposiciones al respecto contenidas en las Legislación especial de asociaciones pueden dar pie para reabrir, a nuestro juicio desacertadamente, el debate sobre la admisión o inadmisión de cualquier ventaja patrimonial para los socios en el $<<$ ánimo de partir entre sí las ganancias $>>$ ex arts. 1665 Cc y 116 Ccom. Así, la LOA incluye en su ámbito objetivo de aplicación a $<<$ las asociaciones que no tengan fin de lucro $y$ que no estén sometidas a un régimen asociativo específico $>>$ (art. $1.2^{\circ}$ LOA) y excluye del mismo a $<<$ Las entidades que se rijan por las disposiciones relativas al contrato de sociedad, cooperativas y mutualidades, así como a las uniones temporales de empresa y a las agrupaciones de interés económico $>>$ (art. $1.4^{\circ}$ LOA). Pero, naturalmente, inexistencia de ánimo de lucro no significa que las asociaciones no puedan realizar actividades económicas. Por ello, se dispone que $<<$ los beneficios obtenidos por las asociaciones

21 Así, por ejemplo, PAZ ARES; Curso; "la integración de las lagunas de los tipos concretos y la interpretación y desarrollo de sus normas puede facilitarse enormemente recurriendo al acervo doctrinal de cada familia de formas sociales (...) Es claro, por ejemplo, que muchos de los problemas que plantea la asociación (...) pueden ser solventados, gracias precisamente al stock de información jurídica que ha generado la Sociedad Anónima" (pp. 485-486). V. además, sobre la consideración del capital como cifra de producción y el debilitamiento de su consideración como cifra de garantía, PAZ-ARES; "La infracapitalización”, pp. 78 y ss[también en Estudios jurídicos en homenaje al Prof. Aurelio Menendez, pp. 78 y ss]; Del mismo autor, "La aportación de uso en las sociedades de capital"; $R d S, 5$ (1995), pp. 33 y ss; MASSAGUER; "El capital nominal de la Sociedad Anónima"; $R G D$; 1990, pp. 5547 y ss; Contra, por ejemplo, ALONSO UREBA; "El capital como cuestión tipológica" en Tratando; pp. 313 y ss, con ulteriores indicaciones todos ellos. 
derivados del ejercicio de actividades económicas incluidas las prestaciones de servicios, deberán destinarse, exclusivamente, al cumplimiento de sus fines, sin que quepa en ningún caso su reparto entre los asociados ni entre sus cónyuges o personas que convivan con aquéllos con análoga relación de afectividad, ni entre sus parientes, ni su cesión gratuita a personas físicas o jurídicas con interés lucrativo $>>\left(\right.$ art. 13. $2^{\circ}$ LOA $)$.

Conforme sostiene el sector doctrinal que estimamos más atendible, para estimar que la asociación es sociedad no es preciso <<estirar $>>$ el concepto de lucro de la sociedad, de forma que sólo comprenda la dimensión objetiva de la obtención de beneficios, sin que sea preciso el ulterior reparto entre los socios (dimensión subjetiva). Este modo de razonar -que obviamente también conduce a afirmar que la asociación es una sociedad- no está sin embargo autorizado porque si se afirma que el lucro es sinónimo de ventaja, y no de ganancia en sentido estricto, desaparecería la distinción entre causa lucrativa y las causas mutualista o consorcial ${ }^{22}$. Pero además, hay que tener presente que el concepto amplio de lucro ha sido argumentado tanto para relativizar o atenuar la relevancia conceptual (normativa) de la índole económica del fin en el contrato de sociedad ${ }^{23}$, como para lo contrario, esto es, para reforzar su inherencia al concepto de sociedad ${ }^{24}$. Y parece evidente que, sirviendo por igual tanto para justificar la pérdida de relevancia del ánimo de lucro como criterio delimitador entre sociedad y asociación, como para justificar la esencialidad del lucro a la noción de sociedad, no puede considerarse un argumento definitivo que justifique ninguna de las dos posturas.

A nuestro juicio, ampliar la noción de lucro para afirmar que la asociación es sociedad no es correcto pero tiene la significación nada desdeñable de suponer la apertura de una brecha a la hora de valorar su relevancia conceptual ${ }^{25}$. Es cierto que, como afirmara la autorizada voz del profesor MENENDEZ, ensanchar el ánimo de lucro "puede provocar menos violencia" 26 al contar con más apoyos positivos, pero no es menos cierto que, como ya afirmara GIRON "no se trata de un problema de contraposición de dos sistema (germánico y latino) igualmente coherentes, sino que hay una incongruencia lógica en uno

22 Así, PAZ-ARES; “Ánimo de lucro y concepto de sociedad”; pp. 732-733 y nota núm. 6; Del mismo autor, Curso, I, pp. 431- 435 y pp. 738-739. Como afirma este autor, la estrategia de estirar el significado de ánimo de lucro "es poco aceptable puesto que desnaturaliza el requisito y lo priva de valor sistemático en las divisiones internas del Derecho de sociedades" (p. 435, en nota).; LLOBREGAT HURTADO; Mutualidad y lucro en la Sociedad Cooperativa; Madrid, 1997, pp. 17 y ss; VICENT- CHULIÂ; Comentario, p. 10283. Resulta significativo, en este sentido, que incluso entre los autores que sostienen la esencialidad conceptual del lucro a la sociedad, la ampliación conceptual del lucro ha sido objeto de críticas. Así, por ejemplo, FONT GALAN/ PINO ABAD; "La relevante causa negocial", pp. 56-57.

${ }^{23}$ Así por ejemplo, MENENDEZ; "Sociedad Anónima y fin de lucro"; pp. 55-57, con ulteriores indicaciones.

24 Así por ejemplo, PANIAGUA; Mutualidad y lucro, pp. 392-400; BERCOVITZ/ BROSETA; "Mutuas de seguros", pp. 37 y 51 y ss; DE LA CÁMARA; Estudios, p. 566; Del mismo autor, "El concepto de sociedad", pp. 482-483; BERCOVITZ; en La Sociedad de Responsabilidad Limitada, pp. 75-78; DE PABLO; "Las personas jurídicas de tipo asociativo" en MARTINEZ DE AGUIRRE ALDAZ/ DE PABLO CONTRERAS/ PEREZ ALVAREZ/ PARRA LUCÁN (DE PABLO, coord); Curso de Derecho Civil, I (Derecho Privado, Derecho de la Persona); Madrid, 2001, pp. 573-574.

25 Así, PAZ-ARES; “Ánimo de lucro”, pp. 732-733.

26 Así, MENENDEZ; "Sociedad Anónima y fin de lucro”, p. 55. 
de ellos"27 motivada, como hemos visto, por exclusivas razones de tradicional recelo histórico hacia las entidades carentes de fin de lucro, hoy plenamente superadas.

Por ello, parece razonable afirmar que si el concepto de lucro que recogen nuestros Códigos a la hora de definir normativamente la sociedad es un concepto estricto omnicomprensivo de dos dimensiones (una objetiva y otra subjetiva), el concepto de lucro que puede manejar la legislación de asociaciones al delimitar negativamente su ámbito objetivo de aplicación no será (por evidentes razones de coherencia normativa) un concepto amplio. Así, la asociación es sociedad pero no porque en el concepto de sociedad el ánimo de lucro pueda entenderse en sentido amplio, sino porque la asociación posee los tres elementos conceptuales esenciales de origen negocial, fin común y comunidad de contribución de la noción de sociedad en sentido amplio. Y si el ánimo de lucro, como elemento conceptual no esencial de la noción de sociedad ha entenderse en sentido estricto, hay que interpretar que las entidades excluidas de la Legislación de asociaciones son aquellas cuyo fin común sea lucrativo en un sentido estricto. La exclusión, por tanto, no abarca a las entidades en las que se produzca cualquier indicio de ventaja económica para los socios (aunque no consista en un incremento patrimonial o ganancia) sino que, por el contrario, la legislación de asociaciones sólo puede estar autorizada para expulsar de su ámbito objetivo, en buena lógica, a aquellas asociaciones en las que la índole material de su fin incluya la obtención (lucro objetivo) y el ulterior reparto (lucro subjetivo).

Este planteamiento es coherente con la finalidad que preside el principio de numerus clausus de tipos sociales en nuestro Derecho, tendente a garantizar que el ejercicio de la actividad mercantil no puede llevarse a cabo fuera del rigor -protección de los terceros que se relacionan con la agrupación y tutela de los derechos de minoría- de los tipos mercantiles $(\text { arts. } 122 \mathrm{Ccom})^{28}$. Por ello, nada impide que las asociaciones desarrollen actividades económicas para lograr la consecución del fin común principal no lucrativo aunque, naturalmente, el beneficio obtenido mediante la realización de la actividad económica deba destinarse íntegramente a la realización del fin común asociativo no lucrativo. La Legislación de asociaciones, así, tan sólo excluye a las entidades en las que se produzca una ganancia económica en sentido estricto para los asociados y, por tanto, prohibe que se realicen atribuciones patrimoniales a los socios con cargo a lo obtenido en el ejercicio de la actividad económica necesaria para la consecución del fin común (art. 13. $2^{\circ} \mathrm{LOA}$ ).

De esta forma, el Legislador acoge el denominado privilegio del fin accesorio Nebenzweckpriviliegs- formulado en el Derecho alemán para la Nichwirschaftlicher Verein o Ideal Verein (21 BGB), conforme al cual, se permite que las asociaciones realicen actividades económicas siempre que no constituyan su fin principal y la explotación de dicha actividad se encamine a garantizar, precisamente, la realización del fin común no lucrativo $^{29}$. Obviamente, los mayores problemas consisten en impedir que por la vía de la

\footnotetext{
27 Así, GIRON; Derecho de sociedades, p. 29.

28 V. por todos, PAZ-ARES; Curso, I, pp. 505-509.

29 Como establece expresamente el Legislador catalán en este sentido, $<<$ se considera que una asociación no tiene ánimo de lucro, aunque desarrolle una actividad económica si el fruto de tal actividad se destina exclusivamente al cumplimiento de las finalidades de interés general establecidas en sus estatutos $>>\left(\operatorname{art} .2 .2^{\circ}\right.$
} 
accesoriedad se enmascaren auténticas agrupaciones de fin económico -Wirtschaftlicher Verein(22 BGB) respecto de las que el Derecho alemán quiere impedir -de ahí los diversos sistemas de adquisición de la personalidad jurídica- que se constituyan bajo tipos distintos de los mercantiles. Por ello, se afirma, ha de exigirse que las asociaciones que realicen actividades económicas se ajusten en la explotación de la actividad mercantil a las determinaciones normativas del Derecho de sociedades de capital (SA, SL, S Coop de consumo o de trabajo asociado) para garantizar la responsabilidad social y la consiguiente tutela de los intereses de terceros.

Entre nosotros, la intención de impedir la burla de las reglas sobre responsabilidad de los tipos mercantiles a través de la Legislación de asociaciones es, naturalmente, la que parece latir tras la prohibición de realización de atribuciones patrimoniales a los socios y a las personas relacionadas con ellos, pero el hecho de que se trate de previsiones normativas cargadas de buenas intenciones no debe impedirnos señalar su previsiblemente escasa utilidad. En efecto si, como parece, lo que preocupa al legislador es la protección de los terceros que se relacionan con la asociación, para evitar el fraude a las normas sobre responsabilidad de los tipos mercantiles -y desincentivar, consecuentemente, la constitución de una asociación allí donde se debería haber elegido un tipo mercantil- es dudosamente efectivo prohibir que la asociación realice atribuciones patrimoniales a los socios o a los terceros que se relacionen con ellos con cargo a los beneficios económicos obtenidos. Y ello porque, de una parte, parece razonable suponer que la asociación tratará de articular primero esas atribuciones patrimoniales como retribuciones por prestación de servicios o contraprestación de cualesquiera otro contrato. De otra, porque nada impide a la asociación realizar gratuitamente la atribución patrimonial a los socios consistente en el beneficio económico de la explotación de la actividad, siempre que las prestaciones gratuitas estén relacionadas con el fin común.

Quizás, para evitar el fraude hubiera sido más efectivo pensar en la transformación en el tipo mercantil que se ha tratado de eludir, cuando la realización de la actividad económica no constituya un medio de realización del fin común no lucrativo sino la causa

LCA). No obstante, sobre la caracterización de la accesoriedad han existido en aquel ordenamiento, tanto doctrinal como jurisprudencialmente, posturas encontradas. Así, o bien se afirma (teoría subjetiva) que la accesoriedad ha de entenderse en sentido de instrumentalidad de la actividad económica que se realiza (mediatamente) para el logro de un fin común principal no lucrativo para los socios, o bien se entiende (teoría objetiva) que la accesoriedad debe medirse por un criterio cuantitativo o de importancia de la actividad económica a realizar por la asociación. Razones de protección de los intereses de tercero justifican una postura ecléctica que atienda tanto a la instrumentalidad como a la entidad (ocasionalidad, grado de organización, etc) de la actividad económica accesoria a la realización del fin común. V. al respecto, por ejemplo, HECKELMANN; "Der Ideaverein als Unternehmer?. Ein Betrag zur Abgrezung des wirtschaftlichen vom Idealverein dargstellt am Beispiel der Futballbundesligen"; AcP, 179 (1979), pp. 1 y ss, especialmente pp. 22-25; REUTER; Münchener Komentar, pp. 360-378, especialmente pp. 360-367; Del mismo autor, "100 Bände BGHZ: Vereins und Genossenschaftsrecht"; ZHR 151 (1987), pp. 355 y ss, especialmente pp. 357-362; SCHMIDT; "Systemfragen des Vereinsrechts", pp. 58-62; Del mismo autor, Gesselschaftsrecht, pp. 554-562, especialmente pp. 556-557; KÜBLER (trad. esp); Derecho de Sociedades; Madrid, 2001, pp. 199 y ss. 
del propio contrato de asociación ${ }^{30}$. En su defecto, parece que la consecuencia jurídica de desbordar el carácter de accesoriedad en las actividades económicas o empresariales de las asociaciones es, en principio, la que se deduce del principio de imposición de forma: ante el defecto en la elección del tipo que comporta la constitución de una asociación para desarrollar una actividad mercantil con carácter principal se producirá la transformación forzosa (ope legis) por frustración de la asociación en el tipo más riguroso de la sociedad colectiva como sociedad general del tráfico $(\text { art. } 122 \mathrm{C} \mathrm{d} \mathrm{C})^{31}$.

30 Tégase en cuenta, en este sentido, que en la justificación de la adopción (transformación ope legis) de un tipo mercantil (SAD) para canalizar el fin común de participación en determinados deportes subyace la situación de sobreendeudamiento de determinados clubes, vinculada a la insuficiencia normativa de las estructuras asociativas para configurar el sistema de responsabilidad de los clubes y de sus administradores. El ejercicio del deporte profesional, se afirma, desborda los estrechos márgenes en los que -en régimen de accesoriedad- el ordenamiento jurídico permite a las asociaciones desarrollar actividades económicas. (V. art. 19 Ley del Deporte y RDSAD de 16 de julio de 1999, sustitutivo del anterior RDSAD de 5 de julio de 1991). V. al respecto, por ejemplo, FRADEJAS RUEDA; "La sociedad anónima deportiva"; RdS, 9 (1997), pp. 206 y ss, especialmente pp. 207-208; CAZORLA PRIETO; Las sociedades anónimas deportivas; Madrid, 1990, pp. 26 y ss; GARCIA LUENGO; "En torno al sistema de fundación de las sociedades anónimas deportivas", en Estudios Jurrídicos en homenaje al Prof. Aurelio Menendez, II, pp. 1817 y ss; GARCIA CAMPOS; Las sociedades anónimas deportivas y la responsabilidad de sus administradores. Algunas alternativas a su régimen jurídico;Madrid, 1996, pp. 20 y ss; IBAÑEZ JIMENEZ; "Estudios sobre el régimen jurídico de las sociedades anónimas deportivas"; $A C, 10$ (1992), pp. 129 y ss, especialmente p. 133; GUTIERREZ GILSANZ; "La conversión de los clubes deprotivos en sociedades anónimas deprotivas"; $R d S, 17$ (2001), pp. 179 y ss, especialmente pp. 180-181; VAREA SANZ; La Administración de la Sociedad Anónima Deprotiva; Madrid, 1999, pp. 29 y ss.

No obstante, puesto que, lege lata, la transformabilidad entre tipos sociales se sujeta en nuestro Derecho al principio de tipicidad normativa (arts. 232. 2 LSA y 224 RRM), dado que es el Legislador el que ha de prever las garantías adecuadas de tutela de socios y terceros cuando se produce un supuesto de sucesión universal o cambio de forma sin que sea necesario disolver, liquidar y constituir nuevamente la sociedad, esta posibilidad tan sólo parece discutible en el plano de política del Derecho, a pesar de que la tendencia legislativa consista en la paulatina ampliación de los supuestos de transformación a todos los tipos de sociedades posibles. V. al respecto, por ejemplo; EIZAGUIRRE; "La transformación de la sociedad de responsabilidad limitada", en Tratando, pp. 863 y ss, especialmente p. 865; VARA DE PAZ; “Transformación: concepto función y caracteres. Supuestos. Transformación de una SA"; $R d S, 16$ (2001), pp. 71 y ss, especialmente pp. 73 y ss. Con todo, URIA/ MENENDEZ/ CARLON; "Transformación, fusión y escisión de la SA"; en URIA/ MENENDEZ/ OLIVENCIA (dirs); Comentario del régimen legal de las sociedades mercantiles; Vol. 1º, Madrid, 1993, pp. 13 y ss, interpretan que el art. 216 RRM autoriza la transformación de una sociedad mercantil en cualquier otra forma social. Como señalan estos mismos autores en Curso, I, " Lo que subyace bajo esta admisión de las transformaciones heterogéneas o mixtas es la tendencia a desdibujar los elementos causales y dogmáticos que tradicionalmente han informado el sistema societario y a convertir las formas sociales en meras técnicas neutras de organización, que prácticamente pueden escogerse y descartarse por motivos de simple conveniencia" (p. 1239).

31 Obviamente, si se entiende que queda fuera del concepto de transformación el cambio de forma social de una asociación o en una asociación, en la medida en "sólo hay transsformación cuando una sociedad cambia de forma y adquiere la vestidura de otra sociedad" y, a tales efectos, se entiende que la asociación no es sociedad, un planteamiento como el descrito en el texto no podría sostenerse. Así, por ejemplo, VARA DE PAZ; "Transformación: concepto, función y caracteres", pp. 71 y 76; Del mismo autor, "Fundación por transformación o cambio de tipo social” en Derecho de Sociedades Anónimas, I, La Fundación, pp. 878 y ss. Con todo, parece evidente que la adopción legislativa del concepto de transformación para aludir a la conversión de clubes deportivos -con equipos profesionales- en SAD y la alusión en la normativa sobre Cooperativas a la transformación entre asociaciones y sociedades cooperativas (V. en relación con la Legislación General, el art. 69 de la LCoop) inclinan a pensar que nuestro Derecho positivo ha ido acogiendo paulatinamente un concepto 


\section{IV.- CONCLUSIONES}

1. El análisis de la sociedad como fenómeno organizativo causalmente neutral conlleva que las nociones de sociedad y asociación, tradicionalmente enfrentadas en atención a la índole material lucrativa o no de su finalidad, no puedan continuar siendo estudiadas como fenómenos agrupacionales antitéticos dotados de regímenes excluyentes. Además, la vertebración del Derecho de sociedades en atención al criterio de la estructuración de los diversos fenómenos agrupacionales pone de manifiesto, de una parte, que el género de aquéllos es la sociedad y no la asociación. De otra parte, la configuración expuesta tiene la virtud de caracterizar el concepto como modelo de organización societaria de estructura corporativa. Así, la asociación (lato sensu) puede entenderse como la forma o tipo básico de las sociedades estatutarias de estructura corporativa que cuando queden sometidas (stricto sensu) a la legislación específica de asociaciones por carecer de capital social (arg. ex art. 3 LSA y LSL) deberán perseguir una finalidad diferente de la lucrativa (arts. 1. $2^{\circ}$ y $4^{\circ}$ LOA) lo que, naturalmente, no excluye la realización de una actividad económica en régimen de accesoriedad (art. 13. $2^{\circ} \mathrm{LOA}$ ).

La caracterización de la asociación como sociedad corporativa no capitalista sin ánimo de lucro permite ubicar concretamente la investigación del tipo -en sus relaciones internas y externas- en la perspectiva contractual que le es propia. Esta perspectiva, por tanto, permite abrir, el debate sobre la posibilidad de aprovechar el caudal dogmático de las soluciones aportadas por el Derecho de sociedades de capital como mecanismo integrador de lagunas del régimen jurídico de la asociación. De esta forma, la elevación de la estructura corporativa a rasgo conceptual principal de la noción de asociación permitirá cubrir las lagunas del régimen jurídico de las asociaciones con la aplicación del régimen jurídico de las SA y SL respetando las especialidades de la asociación (ausencia de capital) cuando falte regulación estatutaria o legal aplicable.

amplio de transformación susceptible de cubrir los cambios de asociaciones en otras formas sociales diferentes. V. en relación con el art. 69 LCoop. ALFONSO SANCHEZ; “Ámbito subjetivo de la transformación en la Legislación Cooperativa (algunos aspectos críticos)"; $R d S, 8$ (1997), pp. 178 y ss; LEON SANZ; "Fusión, transformación y otras modificaciones estructurales de Sociedades Cooperativas", 9 (1997), pp. 25 y ss, especialmente pp. 44 y ss; RODRIGUEZ ARTIGAS; “Transformación de Sociedades Cooperativas"; RdS, 16 (2001), pp. 13 y ss, especialmente pp. 14-15. No puede desconocerse, en este sentido, que también fue justamente la falta de identidad causal entre el fin mutualístico de las Cooperativas y el fin lucrativo de las sociedades el que, originariamente, motivó los recelos hacia la inclusión de la transformación en la Legislación Cooperativa. Como sobradamente demuestra la evolución legislativa de la transformación en este tipo social, en realidad, basta con articular un sistema que garantice el respeto al régimen económico de la Cooperativa, sin desvirtuar los principios que inspiran el régimen cooperativo (en relación por ejemplo al patrimonio irrepartible) para autorizar la transformabilidad entre Cooperativas y otros tipos sociales. 